\title{
Impact of External Appearance on Positive Social Perception
}

Doi:10.5901/ajis/2013.v2n1p131

\section{Mr.sc. Batjar Halili}

\author{
University of Prizren \\ psikologuklinik@hotmail.com
}

\section{Abstract}

By this research, I have aimed to conclude about the rapport which exists between the appearance of students and the impact on this seemingly positive social perception. Many studies conclude that the appearance has significant impact on how people perceive each other. We have selected a sample of 200 students of the University of Prizren and of two university colleges named "Fame" and "Universum" whom have been undergone by this research (research through questionnaires). Results issued by this research are relevant to most of the results obtained by other researches, in which the appearance is particularly important factor in positive social perception. Always according to these results, the appearance of student has a crucial role in how students perceive each other in the context of clothing, physical beauty and the perception of these elements in cahoots with the personality, estimation in faculty, selection at place of work etc.

\section{Introduction}

Firstly, its people appear their self to provide a desired support from others. Because the others often have what we want or what we need, we need to "convince" them to share it with us. A man who wants a job or who is hoping to meet a woman in particular should convey the impression to his interviewer or to the woman that he likes to show that it actually worth.

Then, the self-presentation is a strategic way of gaining control of one's life, a way of increasing the trophies and price reductions (Jones \& Pittman, 1982; SCHLENKER, I980).

Aristotle thought that "there can be no better presentation for a man that his beauty". The external appearance of an individual have been seen by the physiologist Krechmer as an indicator of what hides inside, indicator of the character of human personality.

Krechmer through the external appearance was proving to do the classifications of individuals' temperament and their tendencies to mental disorders.

Our images for your self - our concepts for themselves are partly influenced by what we think others see us.

Halo Effect: This effect consists in the phenomenon whereby initial knowledge on the positive characteristics of an individual, have been used to conclude other its uniformly positive characteristics.

Erving Goffman (1959) presented the dramaturgical perspective, comparing self-introduction to theater, with actors, performances, event sites, scripts, props, roles, background areas, and likeness. Such a phenomenon is observed more often. Political leaders try to profit political supporters through the better physical appearance in the media.

The impact of external appearance on positive social perception is also observed in many other camps of life. The first impressions we create for people depend entirely outwardly they manifest, counting clothes and their style. And then, the choice to be accompanied by someone also depends on his appearance. The people who look cute are perceived as more convincing when speaking in front of 
others. Students believe that the assessment in the school carries with it the physical appearance component.

According to sociologists Muray Webster and James Driskel the advantages which brings the good physical appearance are the same to them which had been brought by advantages being white in comparison to being black, or being male versus female. But, unlike the aforementioned influences, which seem to be declining, the impact that has physical appearance does not show any decline.

Solomon Asch has mentioned the phenomenon of primary effect (Zenden, 1987). According to him, the first impression that we get for others is trying to paint the majority of subsequent impressions for them.

Especially in situations where the first impression is crucial, the dashing men benefit from their attractiveness (Christoph Braun, Martin Gründl, Claus Marberger, Christoph Scherber, Zimmer, 2000).

In a research conducted by Shamo and Stark on the impact of the good physical appearance of the candidates to win a job, has shown that attractiveness was important in the evaluation of applicants. (Shannon, Michael L, Stark, C Patrick, 2003).

This experiment had been done by them with 50 students, who were asked to make the selection of applicants for jobs. The applicants had similar professional knowledge but their appearance change. Data from the experiment showed that the physical appearance of the applicants has been an important factor in evaluating the candidates.

However, we know that physically beautiful people are really more preferable and are looked with more admiration than unattractive people (Eagly et al., I99I; Feingold, 1992; Langlois et al., 2000). The attractive people are seen as more honest (Zebrowitz, Voinesco, \& Collins, I996). They seem to be more likely employed in managerial positions and chose to work in public offices, although the interviewers deny any impact of physical appearance (eg, Budesheim \& DePaola, I994; Mack \& Rainey, 1990). They get smaller fines and bail in felony cases and short sentences in cases of crime (Downs \& Lyons, I991; Stewart, 1980, 1985).

They are paid more: Compared with the being normal attractive, there is an approximately $7 \%$ disadvantage of being unattractive and a $5 \%$ advantage of being very attractive (Hamermesh \& Biddle, 1994). People who are physically attractive are more desirable for romantic relationships.

Even newborn children receive more affection from their mothers when they are delightful (Langlois et al., 1995). Is obvious is estimated when someone is physically attractive. Realizing this, most people try to become more attractive. Taking into account the following data:

$>$ In 2002, the Americans went through approximately 6.9 million surgical and non-surgical cosmetic procedures increased by 228\% since 1997 (American Society for Aesthetic Plastic Surgery, 2003).

$>$ The most popular cosmetic procedure performed over I.6 million times in 2002 was the injection of Botox, which involves injecting a paralyzing toxin into facial muscles not to create wrinkles around the eyes, mouth and forehead.

$>$ Worldwide the cosmetic is an industry with annual revenue of $\$ 20$ billion, and manufacturers of perfumes and eau de cologne sell fragrances estimates by IO billion dollars.

> 5 million Americans currently hold dental prosthesis or other orthodontic tools estimated nearly I million of those adults -most to improve the appearance of their smile.

> Americans spend 35 billion dollars each year on diet foods, weight loss programs, and membership in health clubs.

Consider also the time and money you spend for the hair doing, nail repair, yourself embellishment with jewelry and tattoos, and buying clothes that will hide our weakest physical features and display them more attractive.

And do not forget our more dangerous activities - even life threatening - like poise in the sun, 
keeping severe diet, and use of steroids to build muscle (Leary, Tchividijan, \& Kraxberger, 1994; Martin $\&$ Leary, 200I)

Usually happen that handsome men are perceived as more masculine. The same thing happens even with women who look beautiful. They are perceived as more feminine.

One such phenomenon is welcomed for men but not for women. For many jobs are evaluated primarily the masculine physiognomy, such as being strong, independent, determined, etc... These features usually has been attributed to persons who show masculine character, so beautiful women to whom was attributed the strong female character, encountered difficulties for admission to these jobs. Considering the above findings, it appears that less beautiful women have more advantages in comparison with more beautiful, especially when they seek employment in the management positions.

For this reason, many women today in western countries shape their external appearance by cutting off short hair, by wearing not very feminine or conservative dress, light makeup, etc. always to meet this criterion, so the manifestation of a seemingly more or less masculine. (Reis. et. Al I982).

So, different people in the different cultures conceive also the phenomena in different ways. Even external look and its impact seem to have different character according to different cultures. The impact of appearance has been studied in many nations and cultures, and almost all of these studies have similar conclusions.

We, who live in the Prizren region, have decided to observe this phenomenon exactly in the place where we live so in this region. Through the introduction of this research, we try to provide information on the impact of positive social outwardly perception. The results we obtained are not significantly different from the results that we found in relevant researches.

Through this study were measured variables:

The impact of physical beauty on positive social perception.

The dress and the elegance in positive social perception.

\section{Hypothesis}

We have developed our research by the hypothesis that the "student's appearance is a very important factor in positive social perception."

The way how looks a man is also one of the main factors in job selection..

The students who look pretty have positive assessment by the professors.

The cloths which are worn by the students show their personality.

External appearance is a factor of particular importance for the workplace selection.

The students who look beautiful both in the physical as in clothing generally are perceived as honest persons.

\section{Methods}

This research was done in order to draw conclusions on the relationship between the impact of the external look of the students in the region of Prizren and the positive social perception.

Students selected for this research are students of Prizren State University and those of Prizren Private Universities. Sample of this research are students of the University of Prizren and of the two university colleges named "Fame" and "Universum".

As sample in this research were 200 students. Half of them or $50 \%$ of those who were part of this study were male, while the other half were female.

In order to samples that have been selected to be as representative as possible and enable us to make accurate generalizations as to all University students and two university colleges in Prizren. 
This research has been attended by students from the Education Department, Department of Psychology, Criminology, Law anf Management.

\section{Procedures}

Attending these universities and collaboration with deans and students of those departments in order to help this research to present scientific value.

For the data collection are used questionnaires. In the questionnaire were submitted I2 questions. Data processing is done by the program ESSPS 17.0, where data are simply descriptive statistics.

Questions in this section are proving to ascertain the impact of social positive perception of physical beauty and elegance in dress influence positive social perception, the impact of beauty for career advancement.

The questionnaires were applied to a university and two colleges.

The selection of sample was random. There wereIO0 students of the University of Prizren and IOO students of the two University Colleges "Fame" and "Universum". Students who responded to our questionnaire were students who were selected at random in sections during lectures at various intervals. The questionnaires were applied in the same way to all students of all directions.

Then the data from these questionnaires were collected and analyzed according to the usual statistical analysis procedures.

\section{Results}

I. When we asked what is the most important and valuable thing to a person, more than $\mathrm{IOO}$ of the 200 subjects of our sample have chosen external appearance in positive perceptions of students.

2. Another hypothesis if the external appearance affects the assessment of students by professors $60 \%$ of them have said that this is not the case, 25 of them have said that they rarely happen to find connection to such thing, even when the going is unconscious, I5\% of them expressed pro this element.

3. Results confirming the way of wearing, in a correlation with the honesty, success and level how they are convincing to others.

4. For the connection between the workplace and the external appearance, over $60 \%$ of respondents have said they agree that to succeed in finding a job, should look nice.

5. A particular connection was found between how much the wearing can be representative of someone's personality. $70 \%$ of research subjects conceive a closely connection between the clothing and personality.

\section{References}

Douglas T. Kenrick, Steven L. NEUBERG, Robert B. Cialdini 2005, Social Psychology. Third Edition, Arizona State University.

Zanden, J. 1987. Social Psychology, Fourth edition, Ohio State University.

Shannon, M. L., Stark, P. (2003). The influence of Physical appearance on personnel selection, Social Behavior and Personality

Brawn, K., Gründl, M., Marbeger, C., Scherber, Ch., and Zimmer, A. (2000). More beautiful people have more advantages in life than those less beautiful. Universität Regensburg.

Pango Ylli, (2005). Social Psychology, "University's Library", Tirana, 2005. 